\title{
Hemşirelerde İnovatif İş Davranışının İşgören Performansına Etkisinin İncelenmesi
}

Investigation of the Effect of Innovative Work Behaviour on Employee Performance in Nurses

\author{
Okan ÖZKAN ${ }^{1}$, Özlem ÖZER ${ }^{2}$, Sümeyye ÖZMEN ${ }^{3}$, Fatma ÜZÜMCÜ ${ }^{4}$
}

\section{ÖZ}

$\mathrm{Bu}$ çalı̧̧manın amac1, hemşirelerde inovatif (yenilikçi) iş davranışının işgören performansına etkisini incelemektir. Çalışmanın evrenini bir üniversite hastanesinde görev yapmakta olan hemşireler oluşturmaktadır. Veri toplama aracı, çalışmaya katılmak isteyen tüm hemşirelere dağıtılmış ve 165 hemşireden veri elde edilmiştir. Çalışma sonucunda katılımcıların inovatif iş davranışı ve işgören performansı algılarının yüksek düzeyde olduğu belirlenmiştir. Çalışmada yapıllan korelasyon analizine göre inovatif iş davranışı ile işgören performansı arasında pozitif ve orta düzeyde bir ilişki tespit edilmiş̧ir. Yapılan regresyon analizine göre ise inovatif iş davranışının işgören performansı algısındaki toplam varyansın \%22'sini açıkladığı ve katılımcıların inovatif iş davranışına ilişkin algılarının yükselmesinin işgören performansını istatistiksel olarak artırdığı belirlenmiştir.

Anahtar Kelimeler: Hemşire, İnovatif iş davranışı, İşgören performans1.

\begin{abstract}
The aim of this study is to examine the effect of innovative work behaviour on employee performance in nurses. The universe of the study consists of nurses working in an university hospital. The data collection tool was distributed to all nurses who wanted to participate in the study and data were obtained from 165 nurses. As a result of the study, it was determined that the participants' perceptions of innovative work behaviour and employee performance were at a high level. According to the correlation analysis conducted in the study, a positive and moderate level relationship was found between innovative work behaviour and employee performance. According to the regression analysis, it was determined that innovative work behaviour explains $22 \%$ of the total variance in employee performance perception, and the increase of the participants' perception of innovative work behaviour statistically increases employee performance.
\end{abstract}

Keywords: Nurse, Innovative work behaviour, Employee performance.

Çalışma için bir üniversitenin girişimsel olmayan klinik araştırmalar etik kurulundan izin alınmıştır (Karar No: GO2020/184).

1 Dr. Öğr. Üyesi, Okan ÖZKAN, Sağlık Bilimleri Üniversitesi, Gülhane Sağlık Bilimleri Fakültesi Sağlık Yönetimi Bölümü, okan.ozkan@sbu.edu.tr, ORCID NO: 0000-0001-9491-8696

2 Doç. Dr., Özlem ÖZER, Sağlık Bilimleri Üniversitesi, Gülhane Sağllk Bilimleri Fakültesi Sağlık Yönetimi Bölümü, ozlem.ozer@sbu.edu.tr, ORCID NO: 0000-0002-7238-5371

${ }^{3}$ Dr. Öğr. Üyesi, Sümeyye ÖZMEN, Burdur Mehmet Akif Ersoy Üniversitesi, İktisadi ve İdari Bilimler Fakültesi Sağlık Yönetimi Bölümü, sozmen@mehmetakif.edu.tr, ORCID NO: 0000-0002-3056-0872

${ }^{4}$ Öğr. Gör., Fatma ÜZÜMCÜ, Akdeniz Üniversitesi, Sağlık Hizmetleri Meslek Yüksekokulu Tibbi Dokümantasyon ve Sekreterlik Bölümü, fatmauzumcu@ akdeniz.edu.tr, ORCID NO: 0000-0002-4301-298X

Illetişim / Corresponding Author: ÖZlem ÖZER Geliş Tarihi / Received: 26.02.2021

e-posta/e-mail: $\quad$ ozlem.ozer@sbu.edu.tr

Kabul Tarihi/Accepted: 17.06.2021 


\section{GíRiş}

Günümüzde kuralları hızla değişen dinamik iş dünyasında yenilikleri takip etmenin, teknolojiyi ve inovasyonu geliştirmenin önemi gün geçtikçe daha fazla anlaşılmaktadır. Örgütler açısından inovasyon, rekabet gücü kazanabilmenin, büyümenin ve uzun süre ayakta kalabilmenin en etkili anahtarı olmaktadır. ${ }^{1,2}$ Rekabetçi piyasa içerisinde yenilikçi ürün ve hizmetlerin üretilmesi; kritik bir örgütsel performans kriteri olarak pazara hakim olma, karlılık ve büyüme fırsatları sunmaktadır. ${ }^{1}$ İnovatif bir fikrin sosyal ve ekonomik faydaya dönüşmesi ise temelde insanın çabasını gerektirmektedir. Tecrübelerin, bilgilerin ve fikirlerin değerli bulunacak yeni bir hale dönüştürülme becerisi, insan unsurunu ön plana çıkarmaktadır. Dolayısıyla bu süreçte çalışan kişilerin inovatif iş davranışları, örgütün inovasyonunu geliştirmeye katkı sağlamaktadır. ${ }^{3}$

İnovatif iş davranışı; bir işyerindeki çalışanın yaptığ 1 işleri kolaylaştırması, ürün ya da hizmeti geliştirmesi, yeni imkanlar ile birlikte sunması için rutinden vazgeçilerek yeni çözüm yolları geliştirebilmeyi ifade etmektedir. ${ }^{4}$ İnovatif iş davranış1, yenilikçi fikirlerin oluşturulması ile birlikte daha geniş bir şekilde bu fikirlerin somut çıktılara dönüştürülmesi çalışmalarını kapsamaktadır. ${ }^{5}$ İnovatif iş davranışı; rutinleri değiştirme, işi basitleştirme, hizmeti iyileştirme, tüketicilere yeni teklifler sunabilme gibi pek çok farklı alanda izlenebilmektedir. ${ }^{4}$

Çalışmada incelenen işgören performansı ise bireylerin gösterdikleri çaba sonucunda amaç ve hedeflere ulaşmadaki başarısını, verimliliğini ve etkinliğini gösteren bir kavramdır. ${ }^{6,7}$ İşgören performansı, çalışanın bireysel performansinı ifade etmektedir ve örgütsel performansa doğrudan katk1 sağlayan, örgütsel performansı etkileme gücü yüksek olan önemli bir belirleyicidir. Dolayısıyla işgören performansı ile örgütsel performans arasında pozitif yönlü bir ilişki bulunmaktadır. ${ }^{8,9}$ Challis ve arkadaşları (2002) tarafindan yapılan bir çalışmada da işgören performansı ile üretim performansı arasında pozitif yönlü kuvvetli bir ilişki bulunmuştur. ${ }^{10}$ Örgütlerde istenilen düzeyde etkililik, etkinlik, verimlilik ve devamlılık sağlanabilmesi ancak, performansin hem nitel hem de nicel olarak ölçülebilmesi ve yönetilebilmesi ile mümkündür. ${ }^{6}$

Günümüzde rekabetçi piyasa içerisinde örgütler için işgören performansı yüksek kişilerle çalışmak ve çalışanların performanslarını yönetmek rakiplerine karşı önemli bir avantaj sağlamaktadır. ${ }^{11} \mathrm{Bu}$ nedenle de yöneticiler tarafından işgören performansina gereken ilginin gösterilmesi bir zorunluluk olarak ortaya çıkmaktadır. İşgören performansının yükseltilebilmesi için çalışanların moralinin yüksek tutulması, motive edilmesi, ücretlerinin iyileştirilmesi, ödül mekanizmasının işletilmesi, eșitlikçi ve şeffaf kariyer firsatları sunulması, iş tatminin yükseltilmesi, fikirlerine değer verilmesi, sosyal haklardan yararlanmalarının sağlanması, çalışanlar arasında huzur, yakınlık, samimiyet ortamı oluşturulması gerekmektedir. ${ }^{12,13}$ Ayrıca çalışanların yaptıkları işi anlamlı bulmaları, kendilerini yetkin hissetmeleri, özerk bir yetki alanlarının olduğunu bilmeleri sağlanmalıdır. ${ }^{9}$

Diğer örgütlerde olduğu gibi sağllk kurumlarının başarısı da çalışanların performansına bağglıdır. ${ }^{14}$ Sağlık kurumları emek ve teknoloji yoğun bir örgüt olarak değerlendirilmektedir. ${ }^{15}$ Ayrıca sağlık kurumlarında çalışan personel, ekip halinde işlevsel bağımlılığı yüksek bir sektörde çalışmaktadır. Ekibi oluşturan her bir üye kendi performansinı sergilerken, ekibin performansına da katkı sağlamaktadır. Ekipte çalışan her bir sağlık çalışanının göstereceği çaba, aynı zamanda sağlık hizmetleri kalitesini ve hasta memnuniyetini artırmaktadır. ${ }^{14}$ Ekip olarak bir sinerji ve uyum ile hasta bakımı, tedavi, ameliyat gibi hastanın ihtiyaç duyduğu sağlık hizmetleri en etkili şekilde bu sayede karşılanabilemektedir. $\mathrm{Bu}$ nedenle inovatif düşünceye sahip kişilerin ekibin güçlendirilmesinde önemli bir role sahip 
olduğu ve ekip performansını yükselteceği düşünülmektedir.

Sağlik personeli grubu içerisinde hemşireler, görevleri gereği dönüşüm stratejilerinin kullanımını etkileyebilecek, yenilik sürecinin sorumluluğunu alabilecek ve inovatif davranış gösterebilecek bir konumdadır., ${ }^{416}$ Hemşirelerin sağlık ekibi içerisinde profesyonel bir meslek icra ettiğinin vurgulanmasının, hasta bakım kararlarına saygı gösterilmesinin, mesleki otonomilerinin vurgulanmasının, fikirlerine değer verilmesinin, katılımlarının sağlanmasının ve teşvik edilmelerinin inovatif davranış göstermelerinde etkili ve faydalı olacağı düşünülmektedir. Ayrıca işyerlerinde “çalışan dostu” uygulamalar, çalışan memnuniyetini artırarak, örgütsel güveni oluşturabilecektir. ${ }^{2}$

İnovasyon ile gelişecek belirsizliklere karşı tolerans sağlanması için yanlış bilgilendirmelerin

düzeltilmesi

de gerekmektedir. ${ }^{1}$ Bununla birlikte yapılan çalışmalarda hemşirelerin yönetimden ziyade meslektaşlarından ve gruptaki üyelerden de oldukça fazla etkilendiği tespit edilmiştir. ${ }^{4}$ $\mathrm{Bu}$ nedenle ekip sinerjisinin yükseltilmesi için ekip içerisinde değişimi kolaylaştırıcı informal liderlerle iyi ilişkiler kurulması ve desteklerinin alınması inovatif davranışı artırma yönünde doğru adımlar olabilir.

$\mathrm{Bu}$ çalışmada hemşirelerde inovatif iş davranışının işgören performansına etkisini incelemek amaçlanmıştır. Literatürde örgüt içerisinde güçlendirme ${ }^{9}$, örgütsel sessizlik ${ }^{14}$, örgütsel bağl1l1 $\mathrm{k}^{17}$ gibi unsurların bireysel ve örgütsel performansa etkileri olduğu tespit edilmiştir. Ancak hemşirelerde inovatif iş davranışının işgören performansı üzerine yansımalarını değerlendiren bir araştırmaya rastlanamamıştır. $\mathrm{Bu}$ nedenle bu çalışmanın literatüre katkı sağlayacağı düşünülmektedir.

\section{MATERYAL VE METOT}

\section{Çalışmanın Türü}

Çalışma tanımlayıcı tipte bir araştırmadır.

\section{Evren ve Örneklem}

Çalışmanın evrenini bir üniversite hastanesinde görev yapmakta olan hemşireler oluşturmaktadır. Hastanede toplam 400 hemşire çalışmaktadır. Veri toplama aracı, çalışmaya katılmak isteyen tüm hemşirelere dağıtılmış ve çalışmada 165 kullanılabilir anket elde edilmiștir.

\section{Veri Toplama Aracı}

Çalışmada katılımcıların inovatif is davranıșlarını ölçmek için Jannsen $(2000)^{18}$ tarafından geliștirilen ve Sarıkaya $(2019)^{2}$ tarafından Türkçe'ye çevrilerek geçerlik ve güvenirliği yapılan 9 ifadeli ölçek kullanılmıştır. Ölçekte fikrin üretilmesi, fikrin tanıtımı ve fikrin gerçekleştirilmesi olmak üzere üç boyut yer almaktadır. Ölçekte cevaplar, 1= Hiçbir zaman 5= Her zaman arasında değișen 5'li Likert ölçeğinde puanlanmaktadır. Ölçeğe ilişkin örnek sorular; "İnovatif fikirleri faydalı uygulamalara dönüștürürüm” ve "İnovatif fikirleri gerçekleştirmede insanları harekete geçiririm" şeklindedir.

Katılımcıların işgören performans algılarını ölçmek için, Kirkman ve Rosen $(1999)^{19}$ ile Sigler ve Pearson $(2000)^{20}$ un çalışmalarında kullandığ 1 ve Şantaş ve arkadaşlarının $\quad(2018)^{15}$ geçerlik ve güvenirliğini yaptığ1 "İşgören Performans1 Ölçeği" kullanılmıștır. Ölçek 4 ifadeden ve tek boyuttan oluşmaktadır. Ölçekte yer alan sorular 5'li Likert tipi ölçek ile değerlendirilmektedir $\quad(1=\quad$ Kesinlikle Katılmıyorum, 5= Kesinlikle Katıliyorum). Ölçeğe ilişkin örnek sorular; "Görevlerimi tam zamanında tamamlarım", "İs hedeflerime fazlasıyla ulaşırım" şeklindedir.

\section{Geçerlik ve Güvenirlik Analizi}

Çalışmada ölçeklerin geçerlik ve güvenirliğini test etmek için faktör analizi ve Cronbach alfa katsayısından yararlanılmıștır. İnovatif iş davranışı ölçeğinin geçerliğini belirlemek için yapılan faktör analizi sonucuna göre, bu ölçeğin Sarıkaya $(2019)^{2}$ 'nın çalışmasından farklı olarak tek boyuttan oluştuğu ve toplam varyansin \%63,72'sini açıkladığı belirlenmiştir (KMO= 
$0.915, \chi 2=1067.231, \mathrm{df}=36, \mathrm{p}<0.001) . \mathrm{Bu}$ sonuçlara bağlı olarak ölçek, analizlere tek boyutta dahil edilmiştir. İşgören performansı ölçeği de tek boyuttan oluşmaktadır. Bu sonuç, Şantaş ve arkadaşlarının $(2018)^{15}$ çalışmasının sonuçları ile tutarlılık göstermektedir. Faktör analizi sonucunda bu boyutun toplam varyansin \%67,27'sini açıkladığı tespit edilmiştir $(\mathrm{KMO}=0.758$, $\chi 2=263.024, \mathrm{df}=6, \mathrm{p}<0.001)$.

Çalışmada yapılan güvenirlik analizi sonucunda inovatif iş davranışı ölçeğinin Cronbach alpha değeri 0,93 olarak bulunurken, işgören performansı ölçeğinin Cronbach alpha değeri 0,83 olarak bulunmuştur.

\section{Veri Analizi}

Tüm istatistiksel analizler SPSS 22 programı aracılığıyla yapılmıştır. Verilerin analizinde tanımlayıcı analizler, faktör analizi, güvenirlik analizi, korelasyon analizi ve regresyon analizi kullanılmıştır.

\section{Etik İzin}

Çalışmanın gerçekleştirilebilmesi için bir üniversitenin girişimsel olmayan klinik araştırmalar etik kurulundan (Karar No: GO2020/184) ve araştırmanın yürütüldüğü ilgili hastaneden yazılı izin (Sayı: 26708535900-E.87551) alınmıştır. Hemşirelere çalışmanın amacı ile ilgili bilgi verilmiş ve çalışmaya katılmayı kabul eden kişilerden yazılı onam alınmıştır.

\section{Araştırmanın Sınırlılığı}

$\mathrm{Bu}$ çalışma, bir üniversite hastanesinde çalışan hemşireleri kapsamaktadır. $\mathrm{Bu}$ nedenle çalışmadan elde edilen sonuçlar tüm hemşirelere genellenemez.
Tablo 1'de çalışmaya katılanların demografik özellikleri verilmektedir.

Tablo 1. Katılımcıların Demografik Özellikleri

\begin{tabular}{lcc}
\hline Değişkenler & Sayı & Yüzde \\
\hline Yaş (yıl) & & \\
$\leq 35$ & 49 & 29,7 \\
$\geq 36$ & 116 & 70,3 \\
\hline Cinsiyet & & \\
Kadın & 155 & 93,9 \\
Erkek & 10 & 6,1 \\
\hline Ĕ̆itim Düzeyi & & \\
Lise veya Önlisans & 24 & 14,5 \\
Lisans veya Yüksek Lisans & 141 & 85,5 \\
\hline Medeni Durum & & \\
Bekar & 60 & 36,4 \\
Evli & 105 & 63,6 \\
\hline Să̆lık Sektöründe & & \\
Toplam Çalışma Süresi & & \\
(yol) & & \\
$\leq 15$ & 60 & 36,4 \\
$\geq 16$ & 105 & 63,6 \\
\hline Mevcut Hastanede & & \\
Toplam Çalışma Süresi & & \\
(yıl) & & \\
$\leq 10$ & 63 & 38,2 \\
$\geq 11$ & 102 & 61,8 \\
\hline Toplam & $\mathbf{1 6 5}$ & $\mathbf{1 0 0}$ \\
\hline
\end{tabular}

Tablo incelendiğinde katılımcıların $\% 70,3$ 'ünün 36 yaş ve üzerinde, \%93,9'unun kadın, \%63,6'sının evli ve \%85,5'inin lisans veya yüksek lisans eğitim düzeyine sahip olduğu belirlenmiştir. Katılımcıların \%63,4'ü sağlı sektöründe toplam çalışma süresinin 16 yıl ve üzeri olduğunu ve \%61,8'i de mevcut hastanede çalışma süresinin 11 yıl ve üzeri olduğunu belirtmiştir.

Tablo 2'de katılımcıların inovatif iş davranışı ölçeğine verdikleri puanların ortalamasının 4,00 ve işgören performansı ölçeğine verdikleri puanların ortalamasının 4,16 olduğu görülmektedir. Katılımcıların inovatif iş davranışı ve işgören performansı algıları 5'li Likert Ölçeği ile değerlendirildiği için, ortalama skorlar "5" değerine yaklaştıkça ilgili boyutun düzeyi en yükseği, "1" değerine yaklaştıkça ise en düşüğü göstermektedir. $\mathrm{Bu}$ doğrultuda çalışmaya katılanların inovatif iş davranışı ve işgören performansı algılarının yüksek düzeyde olduğu söylenebilir.

Taşkın Yılmaz ve arkadaşları (2014) tarafından yapılan bir çalışmada başhemşirelerin inovatif davranışlarının yüksek düzeyde olduğu belirlenmiştir. ${ }^{21}$ Bunpin ve arkadaşları (2016) tarafından yapılan bir başka çalışmada ise hemşirelerin inovatif iş davranışı algılarının orta düzeyde 
olduğu saptanmıştır. ${ }^{22}$ Yine Jung ve Yoon (2018)'un çalışmalarında da katılımcıların inovatif iş davranışı algılarının orta düzeyde olduğu tespit edilmiştir. ${ }^{23}$ Mahgoub ve arkadaşlarının (2019) çalışmalarında ise hemşirelerin \%61,1'inin yüksek düzeyde inovatif iş davranışına sahip olduğu belirlenmiştir. $^{24}$ Sağlık bakımında yaşanan değişimler ve hemşirelik uygulamalarındaki yeni yöntemler nedeniyle hastalarla yakından ilgilenen hemșirelerin inovatif iș davranışları göstermeleri önemli bir unsur olmuştur. Dolayısıyla hemşirelerin inovatif iş davranışı algılarının yüksek olması beklenen bir durum olarak değerlendirilmektedir.

Eşkin Bacaksız ve arkadaşları (2018) ile Heves Yılmaz ve Çalışkan (2017) tarafından yapılan çalışmalarda bu çalışmanın sonuçlarına benzer olarak hemşirelerin kendi performanslarını yüksek düzeyde algıladıkları saptanmıştır. ${ }^{25,26}$ Kılınç ve Paksoy (2017), Saygılı ve arkadaşları (2016) ile Şantaş ve arkadaşları (2018) tarafından yapılan çalışmalarda da sağlık çalışanlarının işgören performansı algılarının yüksek düzeyde olduğu belirlenmiştir. ${ }^{14,15,27}$ Hastanelerde işgören performansı, sağlık hizmetlerinin etkili ve verimli sunulması ve dolayısıyla da hastanelerin örgütsel başarısı için önemli rol oynamaktadır. Çalışma sonucunda yoğun iş yükü ile stresli bir ortamda çalışan hemşirelerin performanslarını yüksek düzeyde algilamaları olumlu bir durum olarak değerlendirilmektedir.

Tablo 2. Tanımlayıcı İstatistikler ve Değişkenler Arasındaki Korelasyonlar

\begin{tabular}{lcccc}
\hline Değişkenler & Ortalama & $\begin{array}{c}\text { Standart } \\
\text { Sapma }\end{array}$ & $\begin{array}{c}\text { İnovatif İş } \\
\text { Davranışı }\end{array}$ & $\begin{array}{c}\text { İşgören } \\
\text { Performansı }\end{array}$ \\
\hline İnovatif İş Davranışı & 4,00 & 0,50 & $(1)$ & $(1)$ \\
\hline İşgören Performansı & 4,16 & 0,62 &, $469^{* *}$ & \\
\hline$* * p<0,01$ & & & &
\end{tabular}

Tablo 2'de yapılan korelasyon analizine göre inovatif iş davranışı ile işgören performansı arasında pozitif ve orta düzeyde bir ilişki tespit edilmiştir $(\mathrm{r}=, 469 ; \mathrm{p}<0,01)$. Çiçek ve Işık (2019) tarafindan yapılan çalışmada inovatif iş davranışı ile algılanan işgören performansı arasında $(\mathrm{r}=, 632$; $\mathrm{p}<0,01)$ yüksek düzeyde pozitif yönlü bir ilişki belirlenmiştir. ${ }^{28}$ Zhang ve arkadaşları (2018) tarafından yapılan çalışmada da çalışanların yenilikçi davranışları ile iş performansları arasında pozitif yönde anlamlı bir ilişki olduğu saptanmıştır. ${ }^{29}$ Yuan ve Woodman (2010) tarafindan yapilan çalışmada ise beklenen olumlu performans çıtıları ile inovatif davranışlar arasında pozitif yönde ilişki olduğu sonucuna ulaşılmıştır. $^{30}$ Çalışanların inovatif iş davranışı göstermeleri performanslarına olumlu yansimakta olup bu durum liderlik özelliklerine de etki etmektedir. Nitekim Kwon (2016) tarafindan yapılan çalışmada, hemşirelerin performansı ve inovatif davranışlarının kişisel liderlik ile pozitif yönde ilişkili olduğu saptanmıştır. ${ }^{31}$ Hastanelerde etkin ve kritik rol oynayan hemşirelerin kendilerini geliştirme, hasta bakım kalitesini artırma ve yeni uygulamaları uygulama noktasında inovatif davranışlar göstermeleri büyük önem taşımaktadır. Hemşireler tarafından gösterilecek inovatif iş davranışları bireysel gelişimlerine katkı sağlayıp performanslarına olumlu yönde etki ederek sunulan sağlık hizmetlerini de daha kaliteli ve verimli hale getirecektir.

Tablo 3'te regresyon analizi sonuçları yer almaktadır. İnovatif iş davranışına ilişkin algının işgören performansı üzerindeki etkisini ortaya koymak üzere oluşturulan regresyon modeline ilişkin istatistiksel tahminler modelin anlamlı olduğunu göstermektedir $(F=45,980 ; p<0,001)$. İnovatif iş davranışı işgören performansı algısındaki toplam varyansın \%22'sini açıklamaktadır. Regresyon modelinde, regresyon katsayısının anlamlılığına ilişkin t-testi sonuçları incelendiğinde, katılımcıların inovatif iş davranışına ilişkin algılarının yükselmesi işgören performansını istatistiksel olarak artırmaktadır $(\mathrm{t}=6,781 ; \mathrm{p}<0,001) . \quad \mathrm{Kim}$ ve 
Koo (2017) tarafindan yapılan çalışmada da inovatif davranışların iş performansını olumlu yönde etkilediği belirlenmiştir $(\mathrm{t}=5,263 ; \mathrm{p}<0,01) .{ }^{32}$ Balkar (2015) ile Nasir ve arkadaşları (2019) tarafindan yapılan çalışmalarda da katılımcıların yenilikçi davranışlarının iş performanslarını olumlu yönde etkilediği saptanmıştır. ${ }^{33,34}$ Çalışanların inovatif davranışlar sergilemesi, performanslarını artırarak daha etkin ve verimli çalışmaları sonucunu doğurmaktadır. Hemşireler açısından bakıldığında yenilikçi davranışların sağlık bakım hizmetine doğrudan ve hızlı bir şekilde olumlu yansımaları görülecektir. Çalışanların performansının artması da yoğun rekabet ortamının yaşandığı sağlık sektöründe sürdürülebilir rekabet üstünlüğünü sağlamada kurumlara avantaj sağlayacaktır.

Tablo 3. Regresyon Analizi Sonuçları

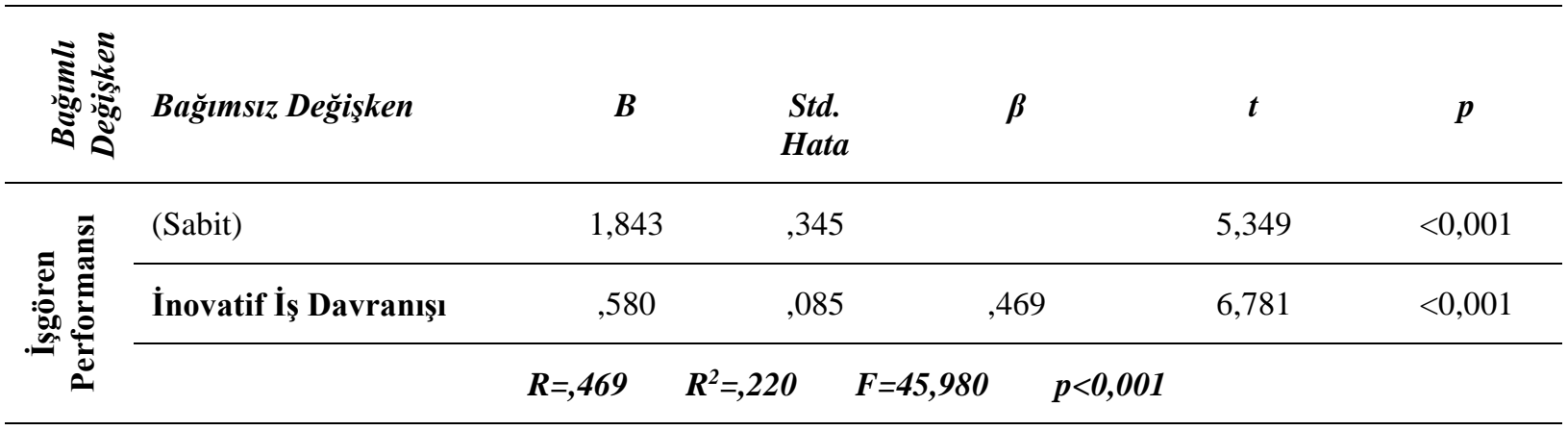

\section{SONUÇ VE ÖNERÍLER}

$\mathrm{Bu}$ çalışma bir üniversite hastanesinde çalışan hemşireler üzerinde yapılmıştır. Çalışma sonucunda hemşirelerin inovatif iş davranışı ve işgören performansı algılarının yüksek düzeyde olduğu tespit edilmiştir. Çalışmada, katılımcıların inovatif iş davranışına ilişsin algılarının yükselmesinin işgören performansını istatistiksel olarak artırdı ğ belirlenmiştir.

Sağl1k hizmetleri sunumunda önemli bir role sahip olan hemşirelerin hızlı gelişen ve değişen sağlık bakım anlayışına uyum sağlamaları büyük önem taşımaktadır. Sağlıkta meydana gelen teknolojik gelişmeler, sağlık bakım hizmetlerindeki güncel ve yeni yöntemler ve hastalarla olan etkileşime yönelik uygulamaların gerçekleşmesinde yenilikçi davranışlar önemli rol oynamaktadır. Hemşirelerin inovatif davranış sergilemeleri performanslarını artırarak hastalara sunulan hizmetlerin kalitesini ve verimliliğini doğrudan etkileyerek hastanelerin sürdürülebilir rekabet üstünlüğüne katkıda bulunmaktadır. $\mathrm{Bu}$ kapsamda hastanelerin hizmet kalitelerini yükseltmek, hemşirelerin iş performanslarını artırmak ve böylece verimlilik sağlayarak rekabet üstünlüğü elde etmek için hemşirelere yönelik kurum içi eğitim, mesleki gelişim seminerleri ve yeni yöntem ve teknolojilere yönelik kursların sağlanmasının yararlı olacağı düşünülmektedir. Ayrıca hemşirelerin yenilikçi fikir, öneri ve yaklaşımları desteklenerek motivasyonlarının artırılması, yenilikçi davranışların kurum kültürünün bir parçası haline getirilmesi ve yenilikçi davranışları etkileyen faktörlerin belirlenerek buna yönelik uygulamalar yapılması önerilmektedir. Yönetsel anlamda inovatif iş davranıșları sergilemenin de hemșirelerin iș tatmini, örgütsel güven ve aidiyet duygularına olumlu yönde etki edeceği düşünülmektedir. 


\section{KAYNAKLAR}

1. Chen, Y, Wang, Y, Nevo, S, Benitez-Amado, J. and Kou, G. (2015). "It Capabilities and Product Innovation Performance: The Roles of Corporate Entrepreneurship and Competitive Intensity". Information \& Management, 52(6), 643-657.

2. Sarıkaya, M. (2019). Kurumsal İtibar Algısının Çalışanın İnovatif Davranışı Üzerindeki Etkisinde Teknoloji Düzeyinin Rolüne İlişkin Bir Araştırma. Doktora Tezi, Pamukkale Üniversitesi Sosyal Bilimler Enstitüsü, Denizli.

3. Chell, E. and Rosemary, A. (2009). "The Identification and Measurement of Innovative Characteristics of Young People: Development of the Youth Innovation Skills Measurement Tool”. Research Paper, Nesta.

4. Amo, B.W. (2006). "Employee Innovation Behaviour in Health Care: The Influence from Management and Colleagues”. International Nursing Review, 53, 231-237.

5. Devloo, T, Anseel, F, De Beuckelaer, A. and Salanova M. (2015). "Keep the Fire Burning: Reciprocal Gains of Basic Need Satisfaction, Intrinsic Motivation and Innovative Work Behaviour". European Journal of Work and Organizational Psychology, 24(4), 491-504.

6. Tutar, H. ve Altınöz, M. (2010). “Örgütsel İklimin İsgören Performansı Üzerine Etkisi: Ostim İmala İşletmeleri Çalışanları Üzerine Bir Araştırma”. Ankara Üniversitesi Siyasal Bilgiler Fakültesi Dergisi, 65(2), 196-218.

7. Bekiş, T, Bayram, A. ve Şeker, M. (2013). "Kurumsa İtibarın İşgören Performansı Üzerindeki Etkisinin Belirlenmesine Yönelik Bir Araştırma”. Uluslararası Alanya İşletme Fakültesi Dergisi, 5(2), 19-27.

8. Kesen, M. ve Kaya, N. (2016). "Calıșan Performansının Örgütsel İmaj ve Psikolojik Sermaye Bağlamında İncelenmesi: Vakıf Üniversiteleri Örneği”. The Journal of Academic Social Science Studies, 46, 187-198.

9. Çöl, G. (2011). “Algılanan Güçlendirmenin İşgören Performansı Üzerine Etkileri”. Doğuş Üniversites Dergisi, 9(1), 35-46.

10. Challis, D, Samson, D. and Lawson, B. (2002) "Integrated Manufacturing, Employee and Business Performance: Australian and New Zealand Evidence", International Journal of Production Research, 40(8), 1941-1964.

11. Yelboğa, A. (2006). "Kişilik Özellikleri ve İş Performansı Arasındaki İlişkinin İncelenmesi”. İş, Güç Endüstri İlişkileri ve İnsan Kaynakları Dergisi, 8(2), 196-211.

12. Uygur, A. (2007). “Örgütsel Bağlılık ile İsgören Performansı İlişkisini İncelemeye Yönelik Bir Alan Araştırması". Ticaret ve Turizm Eğitim Fakültesi Dergisi, 1, 71-85.

13. İraz, R. ve Akgün, Ö. (2011). “Örgütsel Bağlılığıın Çalışan Performansı Üzerine Etkilerini Ölçmeye Yönelik Bir Araştırma”. Selçuk Üniversitesi Sosyal Bilimler Meslek Yüksekokulu Dergisi, 14(1-2), 201-224.

14. Saygılı, M., Erigüç, G. ve Özer, Ö. (2016). "Sağlık Çalışanlarının Örgütsel Sessizlik ve Çalışan Performans Düzeylerinin Belirlenmesi”. The Journal of Academic Social Science Studies, 49, 485-500.

15. Şantaş, F, Şantaş, G, Özer, Ö. ve Güleç, M.B. (2018) "Sağlık Çalıșanlarında Örgütsel Kronizm ve İşören Performansı Arasındaki İlișkinin İncelenmesine Yönelik Bir Araştırma”. Eskişehir Osmangazi Üniversitesi İktisadi ve İdari Bilimler Dergisi, 13(3), 37-54.
16. Trofino, J. (2000). "Transformational Leadership: Moving Total Quality Management to World-Class Organizations". International Nursing Review, 47(4), 232-242.

17. Güner, A.R. (2007). Sağlık Hizmetlerinde Örgütsel Bağlılık, İşe Bağlılık ve İş Tatmini Arasındaki İlişskilerin Modellenmesi. Yüksek Lisans Tezi, Akdeniz Üniversitesi Sosyal Bilimler Enstitüsü, Antalya.

18. Janssen, O. (2000). "Job Demands, Perceptions of Effort Reward Fairness and Innovative Work Behaviour". Journal of Occupational and Organizational Psychology, 73(3), 287-302.

19. Kirkman, B.L. and Rosen, B. (1999). "Beyond SelfManagement: Antecedents and Consequences of Team Empowerment". Academy of Management Journal, 42(1), 58-74.

20. Sigler, T.H. and Pearson, C.M. (2000). "Creating an Empowering Culture: Examining the Relationship Between Organizational Culture and Perceptions of Empowerment". Journal of Quality Management, 5, 27 52

21. Taşkın Yılmaz, F, Şen, H.Ş. ve Demirkaya, F. (2014) "Başhemşirelerin Yenilikçilik ve Risk Alma Davranıșlarının Belirlenmesi”. Balıkesir Sağlık Bilimleri Dergisi, 3(3), 147-154.

22. Bunpin, J.J.D, Chapman, S, Blegen, M. and Spetz, J. (2016). "Differences in Innovative Behavior Among Hospital-Based Registered Nurses". JONA: The Journal of Nursing Administration, 46(3), 122-127.

23. Jung, H.S. and Yoon, H.H. (2018). "Improving Frontline Service Employees' Innovative Behavior Using Conflict Management in the Hospitality Industry: The Mediating Role of Engagement". Tourism Management, 69, 498507.

24. Mahgoub, A.E.F, Mostafa Shazly, M. and Mohammed El-Sayed, S. (2019). "Relationship between Work Environment and Innovative Behavior among Staff Nurses”. Egyptian Journal of Health Care, 10(3), 64-77.

25. Eşkin Bacaksız, F, Tuna, R. ve Seren Harmancı, K.A. (2018). "Sağlık Çalışanlarında Performans ve Örgütsel Sinizm İlişkisi: Hemşireler Üzerinde Bir Araştırma". ACU Sağlık Bilimleri Dergisi, 9(1), 52-58.

26. Heves Yılmaz, S. ve Calıșkan, H. (2017). "Hemșirelerde Kültürel Yetkinlik Algısının İş Performansına Etkisi”. Sağlıkta Performans ve Kalite Dergisi, 13(1), 127-149.

27. Kılınç, E. ve Paksoy, H.M. (2017). "Sağlık Çalışanlarında Performans Algı Düzeyinin Bazı SosyoDemografik Değisskenlere Göre İncelenmesi”. Selçuk Üniversitesi Sosyal Bilimler Meslek Yüksekokulu Dergisi, 20(2), 151-159.

28. Ciçek, B. ve Ișık, M. (2019). "Algılanan Calıșan Performansı ile İşletme Performansı Arasındaki İlişkide Yenilikçi İs Davranıșının Düzenleyicilik Etkisi”. Eskişehir Osmangazi Üniversitesi İktisadi ve İdari Bilimler Dergisi, 14(3), 699-712.

29. Zhang, Y, Zhang, J, Forest, J. and Chen, C. (2018). "The Negative and Positive Aspects of Employees' Innovative Behavior: Role of Goals of Employees and Supervisors". Frontiers in Psychology, 9, 1871.

30. Yuan, F. and Woodman, R.W. (2010). "Innovative Behavior in the Workplace: The Role of Performance and Image Outcome Expectations". Academy of Management Journal, 53(2), 323-342. 
31. Kwon, J.O. (2016). "Nursing Performance and Innovative Behavior as Factors Affecting The SelfLeadership of Geriatric Hospital Nurses". The Korean Journal of Health Service Management, 10(1), 53-66.

32. Kim, M.S. and Koo, D.W. (2017). "Linking LMX, Engagement, Innovative Behavior, and Job Performance in Hotel Employees". International Journal of Contemporary Hospitality Management, 29(12), 30443062 .

33. Balkar, B. (2015). "The Relationships Between Organizational Climate, Innovative Behavior and Job Performance of Teachers". International Online Journal of Educational Sciences, 7(2), 81-92.

34. Nasir, N, Halimatussakdiah, H, Suryani, I., Zuhra, S.E., Armia, S. and Mahdani, M. (2019). "How Intrinsic Motivation and Innovative Work Behavior Affect Job Performance." In 1st Aceh Global Conference (AGC 2018-Banda Aceh, Indonesia), 606-612, Atlantis Press. 